\title{
Coping with a Money Crunch: Values, Goals, and Standards ${ }^{1}$
}

Josephine Turner, Katey Walker and Michael S. Gutter ${ }^{2}$

Consumer choice is a fundamental problem for all human beings. It is also a complex problem because there are many new products, services, and ways of doing things being developed all the time. It's even more difficult to make decisions when you're experiencing a money crunch.

The choices we make, consciously or unconsciously, determine to a large extent what we get out of life. Setting your goals for individual or family spending is not enough; we need the ability to carry out the activities which will accomplish the goals. Much research shows that the biggest determinant of what we get out of life is what we

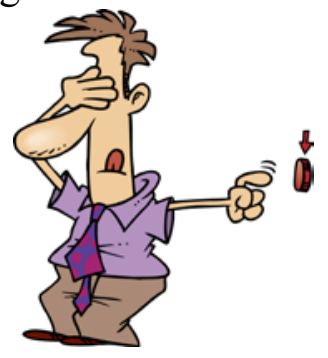
want out of life. The amount of money or other resources available are important, but do not guarantee happiness. It is quite possible to be wealthy and unhappy.

All people need food, shelter, clothing, transportation, recreation, and social interaction. Yet many are not at all satisfied by supplying only these needs. They want a great many things they do not "need," often more intensely than they want what is required for basic survival.

\section{Needs vs. Wants}

- Needs are usually defined as things which are essential for survival. They include both physical and social or psychological necessities.

- Wants are usually defined as all the other things we would like to have, but could survive without.

Both needs and wants are influenced by the society in which we live. Our wants over time are unlimited, while the resources available to satisfy them are limited. This makes it necessary to decide on goals and set priorities. When you've experienced a financial crisis such as losing your job, serious thinking about what's really important to you is vital.

\section{Know Yourself}

People need to know themselves if their resources are to provide maximum satisfaction

1. This document is FCS7006, one in a series of the Department of Family, Youth and Community Sciences, Florida Cooperative Extension Service, Institute of Food and Agricultural Sciences, University of Florida. Original publication date: November 1, 1984. Revised March 2009. Please visit the EDIS Web site at http://edis.ifas.ufl.edu

2. Written by Katey Walker, former Family Resource Management Specialist, Department of Family, Youth and Community Sciences; revised by Josephine Turner, professor, Family, Youth and Consumer Economics, and Michael S. Gutter, assistant professor, Family Financial Management, Department of Family, Youth and Community Sciences,; Institute of Food and Agricultural Sciences; University of Florida; Gainesville 32611. 
and a high quality of life. Many people tend to be uncomfortable and dissatisfied with themselves because they talk about one set of values, while their behavior shows another and very different set of values. Personal satisfaction grows out of "getting your act together," or matching your values and your behavior. Reaching some sort of balance or compromise among conflicting goals is fundamental to getting through a crisis with the least stress possible.

It is essential to

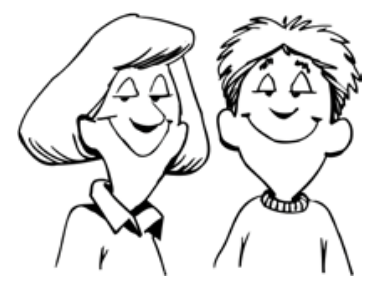
solve such conflicts before a new and satisfactory pattern of living can be developed.

\section{Plan to Achieve Your Goals}

In order to plan, you must first think about your goals. This includes both long-term and short-term goals, because it is vital to keep these two kinds of goals working together instead of at cross purposes. If you think only about longterm goals, your planning may be vague and unrealistic. You end up having wishes and dreams instead of solid accomplishments. On the other hand, if you think only of short-term goals, you may find that you are not getting anywhere because you never come close to accomplishing your long-term goals.

During a financial crisis, the main goal is usually to mobilize the resources you still have or can develop to get through the stress period. This calls for decisions about what is really important. You must learn how to set priorities.

\section{Reaching Your Goals}

You can get there from here. Having goals seems to increase energy, because suddenly your energy is directed in one channel instead of flowing in many undefined directions.

Almost all successful people are goalsetters - in both their personal and financial lives. They do not let temporary setbacks keep them from moving forward.

One of the primary purposes of goal-setting is to force yourself to think through the situation and then to project into the future and figure out how your goals can be accomplished and what tools you will need to reach those goals.

Some good, hard thinking is required during the goal-setting process. For example, it is easier and less painful to seek product information than to decide why we want or need a particular product or service. But even a "good" product is not satisfying if it doesn't fit our needs. No product is "good" if we buy it at a time when our money resources are needed for something more important.

\section{Taking Action}

Setting up goals is not enough by itself. We also need the motivation and ability to take action towards accomplishing these goals.

Focus on short-term, measurable goals. As you are able to reach these, your confidence about reaching longer-term goals will also improve.

We need a mechanism for coordinating goals, plans, and actions. In money management, we make a budget to distribute the income so it goes to the most important needs. In time management, we make a schedule or a "things To Do" list to help us decide what to do now and when in the future we will do other things.

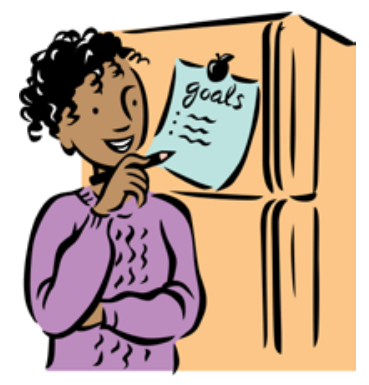

One of the big temptations during a period of financial stress is to buy something, or to go out to dinner, or do something else expensive to try to relieve boredom or frustration. You may call it "treating yourself," but when you give in to that impulse too often or too extravagantly, the money is no longer available to put toward something more important and you have lost a chance to move closer to your goal.

Instead, find an alternate form of stress release. Try taking a walk or exercising, talking with someone you trust, or listening to music. Find a hobby that may not cost money. Any of these alternatives are better than going to the mall. 
Archival copy: for current recommendations see http://edis.ifas.ufl.edu or your local extension office.

Coping with a Money Crunch: Values, Goals, and Standards

page 3

Revise Your Standards

Standards differ from family to family and from person to person within a family, because each has different values. Standards are not easily changed. Families often experience conflicts and stress when they try to develop

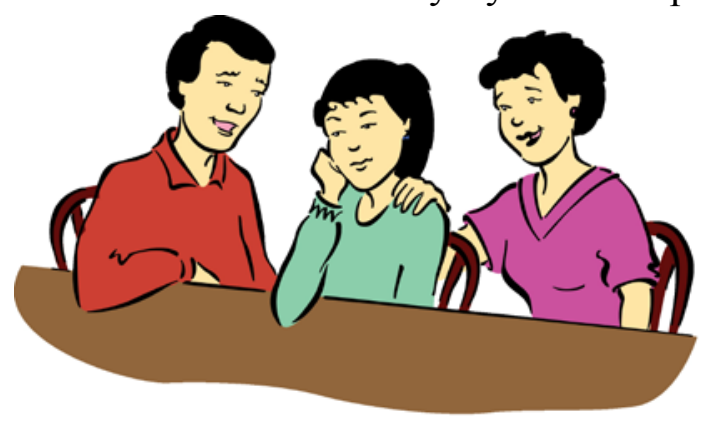

new standards to meet changes in their lives. A lot of family discussion and strong efforts to maintain a positive outlook are needed during a period of unemployment or other financial difficulty. Whether you're single or married, discussing the problems with friends is very helpful, particularly with those who have been through the same situation.

These same ideas can work when you have a loss of purchasing power from inflation or because of medical emergencies, a change of career, or even retirement. Make wise use of the resources you still have, set new goals, and make a definite plan to move toward your goal. Remember, it's not the outside situation that determines happiness or whether you can meet your goals.

March 2009 